\title{
AUDITORIA EM ENFERMAGEM: IMPLANTAÇÃO E DESENVOLVIMENTO NO HOSPITAL UNIVERSITARIO DA UNIVERSIDADE DE SAOO PAULO
}

\author{
Sandra Honorato da Silva* \\ Diley Cardoso Franco Ortiz** \\ Helena Eri Shimizu*** \\ Márcia Toth***
}

SILVA, S.H. da; ORTIZ, D.C.F.; SHIMIZU, H.E.; TOTH, M. Auditoria em enfermagem + implantação e desenvolvimento no Hospital Universitário da Universidade de São Paulo. Rev. Esc. Enf. USP, São Paulo, 24(2):199-209, ago. 1990

$O$ trabalho relata a experiência do Departamento de Assistência de Enfermagem do Hospital Universitário da USP, da implantação e desenvolvimento do processo de auditoria retrospectiva para avaliação de suas atividades, como instrumento de controle e manutenção da qualidade da assistência de enfermagem prestada d comunidade. Descreve as várias etapas, instrumentos e relatórios utilizados, assim como o emprego dos resultados da auditoria para revisão dos programas assistenciais e educacionais desenvolvidos pelo Departamento.

UNITERMOS: Auditoria em enfermagem. Assistência de enfermagem.

\section{INTRODUÇÃO}

O Hospital considerado uma organização de alta complexidade, exige que as atividades desenvolvidas em seus diversos departamentos estejam coordenadas de maneira a garantir eficiência e eficácia dos serviços prestados e conseqüente alcance dos objetivos organizacionais.

O Departamento cic Enfermagem, parte integiante $c$ fundamental da organização hospitalar, deve desenvolver cientficamente suas atividades técnico-assistenciais e administrativas, visando não só a garantia da qualidade da assistência e ensino prestado à comunidade como sua perfeita integração e participação no processo de desenvolvimento organizacional.

Partindo dessa premissa, o Departamento de Enfermagem do Hospital Universitário, tomando por base uma filosofia assistencial, que visa primordialmente $o$ atendimento do ser humano, em suas necessidades

- Professor Assistente da Fscola de Enfermagem da Universidade de sto Paulo e Diretor de Divisho do Departamento de Assistencia de Fnfermagem do Hospital Universitário da Universidade de Bao Paulo.

* Infermeiro Incarregado da Unidado da Clínica Cirárgica do Departamento de Assistencia de Infermagem do Hospital Universitário da Universidade de săo Paulo.

** Enfermeiro Encarregado da Unidade de Clinica Médica do Departamento de Assistencia do Fnfermagem do Hospital Universitário da Universidade de Sá Paulo. 
humanas básicas direcionando essa assistência para o auto-cuidado, decidiu desenvolver suas atividades, considerando as funções do processo administrativo, uma vez que, segindo CHIAVENATO (1985) "planejamento, organização, direção e controle estão intimamente ligados entre si, são interdependentes e interagentes".

A auditoria em enfermagem, representa a função de controle do ciclo do processo administrativo, sob o qual o Departamento de Enfermagem conduz suas funções básicas. Constitui o meio pelo qual - Departamento de Enfermagem verifica se os resultados atingidos na assistência de enfermagem prestada, estão de acordo com os objetivos traçados.

Para CHIAVENATO (1981) a auditoria é um "sistema de revisão e controle, para informar a administração scbre a eficiência e eficácia dos programas em desenvolvimento. Sua função não é somente indicar as falhas e os problemas, mas também, apontar sugestões e soluções, assumindo portanto um caráter eminentemente educacional.

AQUINO (1980) consiciera auditorił como uma investigação profunda sobre o sistema, em seus aspectos qualitativos e não apenas rotineiros e burocráticos, podendo ser definida como um conjunto de técnicas analíticas destinadas a efetuar diagnósticos, prognósticos e recomendações.

Para CHIAVENATO (1985) o controle é feito através de quatro fases distintas:

- estabelecimento de padrões de desempenho;

- mensuração do desempenho a ser controlado;

- comparação do desempenho atual com o padrão e

- tomada de ação corretive par’ ajustar o desempenho atual ao padrão desejado.

Para cumprir a função controle do processo administrativo, o Departamento de Enfermagem precisa definir seus objetivos, estabelecer seus elementos estruturais, assim como os padrões de desempenho aceitáveis, o que torna possivel uma análise adequada da eficiência e eficácia das atividades desenvolvidas.

Segundo KURCGANT (1976) "o destino profissional da enfermeira é regido pela avaliação coos resultacios de suas ações de enfermagem no campo de trabalho".

Adotando-se a avaliação como um método para determinar a ex. tensão dos objetivos alcançados, fica implícita a mensuração da qualidade da assistência prestada, meta primordial de todo o trabalho desenvolvido pela enfermagem.

Para HOWARD (1986) um programa de garantia de qualidade faz com que a assistência de enfermagem prestada aos pacientes encontre padrões aceitáveis. 


\section{IMPLANTAÇĀO E DESENVOLVIMENTO DA AUDITORIA}

O Grupo de Padrões c Auditoria em Enfermagem no Hospital Universitário, foi criado em 1982, para assessorar o Departamento de Enfermagem na avaliação da mensuração da qualidade da assistência de enfermagem prestada na Instituição, tendo como proposta uma análise retrospectiva da assistência de enfermagem, ou seja, uma análise criteriosa dos registros de enfermagem contidos no prontuário.

Para KRON (1978) o objetivo do processo de auditoria é "a avaliação, não somente da eficácia da assistência que o paciente recebe, mas também da integridade e exatidão da demonstração dessa assistência no prontuário".

Num primeiro momento, foi elaborado o regimento do grupo de trabalho, onde ficaram determinadas as finalidades da auditoria, competência do grupo e os critérios a serem observados para auditoria retrospectiva.

Para viabilizar a proposta de auditoria foi construido um instrumento de auditoria tomando por base padrões assistenciais, passíveis de mensuração retrospectiva, adotados para cada unidade de internação. Para minimizar a subjetividade e atingir uma maior homogeneidade dos dados coletados, foram descritos os critérios e valores a serem observados para o preenchimento do instrumento de auditoria.

O instrumento criado previa a auditoria de seis áreas de atuação da enfermagem.

I. Levantamento de dados na admissão;

III. Prescrições e evoluções de enfermagem;

III. Anotações de enfermagem;

IV. Execução de ordens médicas;

V. Procedimentos de enfermagem;

VI. Condições de alta. foram:

Os critérios inicialmente descritos a serem observados na auditoria

- a assistência de enfermagem prestada ao paciente durante a hospitalização e registrada em prontuário seria avaliada desde a internação até a alta;

- fariam parte cla amostra de cada mês todos os prontuários cujo tempo de internação estivesse cientro da média de permanência na unidade;

- os prontuários a serem auditados seriam determinados através de sorteio;

- do total de altas do mês, que estivessem dentro da média de permanência, seriam auditados $10 \%$; 
- os prontuários de óbito seriam analisados integralmente, independente de sorteio.

Para um desenvolvimento adequado do trabalho, os elementos do grupo sofreram treinamento específico. Para SA (1969) o treinamento significa que para desenvolver uma tarefa é preciso haver ensino e instrução de forma planejada e sistematizada, não permitindo que a aprendizagem se processe por experiência ou tentativa de êrro.

Com a aplicação do instrumento de auditoria, segundo critérios estabelecidos, observou-se que ao se trabalhar somente com prontuários de pacientes cujo período de internação estivesse dentro da média de permanência da unidade, esiaria sendo excluída da amostra uma parcela importante de pacientes com permanência prolongada e cuja assistência de enfermagem deveria, também, ser objeto de análise.

Para contornar o problema detectado, foi introduzida uma modificação. Como na ocasião a média de permanência estivesse $\mathrm{cm} 15$ dias, foi estabelecido:

- fariam parte da amostra para sorteio os prontuários correspondentes ao total de altas do mês;

- quando o periodo de hospitalização do paciente sorteado para auditoria fosse de até 15 dias, seriam analisados todos os dias de internação;

- quando o periodo de hospitalização ultrapassasse 15 dias seriam auditados os 5 primeiros dias - 5 dias intermediários e os 5 dias finais de internação.

O tempo médio utilizado para auditoria de um prontuário era de duas horas.

Em 1985 foi detectada a necessidade de reavaliação do instrumento, sendo então introduzida mais uma área para análise - "Retorno de Enfermagem". Como nessa ocasião a média de permanência estivesse em 9 dias, o critério anteriormente estabelecido para 15 dias foi modificado para os 9 dias.

Nessa época todos os Serviços do Departamento de Enfermagem, eram auditados através de instrumento específico, sendo auditados por mês uma média de 25 prontuários, equivalente a 4 prontuários/mês por auditor. Os auditores realizavam seu trabalho, fora do horário regular de trabalho, o que significa uma sobrecarga individual e de grupo. caçöes:

No final de 1986, o grupo de padrões estabeleceu algumas modifi-

- reformulação do instrumento de auditoria, com redução do número de itens a serem auditados, e redefinição dos critérios de preenchimento do instrumento para minimizar os aspectos de subjetividade;

- elaboração de um instrumento único para todos os Serviços, com instrumento complementar para as áreas de Centro Obstétrico e Centro Cirúrgico (Anexos I, II e III); 
- ampliação do número de componentes do grupo, para que houvesse uma redução da carga de trabalho de cada elemento;

- os enfermeiros auditores passaram a receber folgas em proporção ao tempo utilizado para auditoria;

- todos os enfermeiros do grupo de auditoria e os Diretores de Serviço, receberiam um curso de auditoria, para que a participação de todos pudesse ser mais efetiva.

$\mathrm{O}$ atual instrumento (Anexo I) favoreceu a auditoria nos aspectos de facilidade e homogeneidade no preenchimento e redução do tempo de análise. Para manter uma dinâmica que possibilite o desenvolvimento) adequado do trabalho, são auditados, por mês, 3 prontuários de cada unidade.

Para que a auditoria retrospectiva possa desenvolver-se de maneira adequada, é necessário uma perfeita interação entre o Departamento de Enfermagem e o Serviço de Arquivo Médico e Estatística (SAME). Ambos devem estabelecer a forma como os prontuários serão solicitados, e a área do SAME onde os auditores desenvolverão seu trabalho.

\section{RESULTADOS DA AUDITORIA}

Os resultados encontrados nas auditorias dos prontuários de cada unidade, após sofrerem grupamento e análise, precisaram ser colocados em relatórios, que expressem quantitativa e qualitativamente os dados encontrados para que os mesmos possam ser conhecidos pelo grupo diretamente envolvido no trabalho.

Para SA (1969) é no relatório de auditoria que o auditor expõe o estado em que encontrou o que foi objeto de suas verificações, descrevendo-o com clareza, técnica e precisão.

$\mathrm{Na}$ fase inicial do trabalho de auditoria foi estabelecido um esquema de relatórios trimestrais. No entanto, observou-se que o espaço de tempo entre eles era insuficiente para discussão do achado, propostas de melhoria de atuação nas unidades e reciclagem. Atualmente, o esquema prevê a elaboração de relatórios semestrais.

No relatório os dados são tabulados em cada uma das partes do instrumento (I a VI), atribuindo-se valores para cada item de acordo com seu preenchimento. Em seguida é feita uma análise sumária dos dados obtidos, acrescidos de sugestões para cada uma das unidades auditadas.

O esboço inicial do relatório de cada unidade é discutido em reunião do grupo de padrões e auditoria e posteriormente aprovado. Em seguida, os relatórios são discutidos e analisados em reunião de Diretoria do Departamento. Recebem cópias do relatório o Departamento de Enfermagem, o Serviço de Educação Continuada e demais Serviços do DE. A cada Serviço em conjunto com Educação Continuada cabem as providências necessárias para correção dos problemas detectados. 
Para CHIAVENATO (1985) a ação corretiva "é a função básica do controle através da qual as providências são tomadas para eliminar as variâncias significativas entre 0 desempenho atual e 0 desempenho planejado".

\section{CONSIDERAÇOES FINAIS}

Hoje, torna-se impraticável um trabalho de enfermagem, desenvolvido nos esquemas anteriormente adotados, onde planejamento e con. trole aparecem de maneira desordenada e descontínua.

Com a implantação de um processo de auditoria contínua, o Departamento de Enfermagem passa a dispor cie informações corretas que funcionarão como elo de ligação entre os planos e as decisões subsequientes.

Para ARAÚJO (1978) "um programa de auditoria constitui um alerta constante para o enfermeiro manter-se em suas funções, garantindo a qualidade assistencial, empenhando-se na aquisição de melhores padrōes. O doente receberá uma assistência cada vez mais aperfeiçoada, o que lhe assegura recuperação rápida, com menos riscos e principalmente a certeza de receber o que necessita para resolver seu problema".

Ao estabelecer formas organizadas e cientificas para a condução do trabalho em enfermagem, não só estaremos garantindo a qualidade da assistência e contribuindo para a melhoria do atendimento de saúde, como também, contribuindo para o desenvolvimento técnico-científico e social da nossa profissão.

SILVA, S.H. da; ORTIZ, D.C.F.; SHIMIZU, H.E.; TOTH, M. Nursing audit: implantation and development in Hospital Universitário da Universidade de São Paulo. Rev. Esc. Enf. USP, São Paulo, 24(2):199-209, Aug. 1990.

The study reports an experience carried aut by the Departamento de Assistência de Entermagem do Hospital Universitário da USP, the implantation and development of the retrospective auditory process for the evaluation of their activities as an instrument for control and maintenance of the quality of nursing care given the community. It describes the various steps, instruments and reports used, as well as the use of the auditory's findings for reviewing the assistential and educational programs developed by the department.

UNITERMS: Nursing audit. Nursing care evoluation.

\section{REFERENCIAS BIBLIOGRAFICAS}

AQUINO, C.B. de. Adminintraglo de recurson humenos: uma introduclio. Bho Paulo, Atlan, 1980. $270 \mathrm{p}$.

ARAOUJO, M.V. de et alli. Auditoria em enfermagem. Bov. Brac. Innf., Brasille, 31(4): 466-77, out./dez. 1978.

CHLAVENATO, I. Administracio de recuras humanos. 2.ed. sao Paulo, Atlas, 1981. V. 8.

CHLAVinato, I. Adminietracio: teoria, proconso - pritica. S6o Paulo, Mc Graw-Hill, 1985. $381 \mathrm{p}$.

HOWARD, K.P. Improving a quality assurance program. Nurm. Managa. Chicago, 17(4):88-4, Apr. 1988.

KRONT, T. Manual de enformarem. 4.ed. Rio de Janeiro, Interamericana, 1978. $251 \mathrm{p}$.

KURCGANT, P. Auditoria em enfermagem. Rev. Bran. Bnf., Bresilia, z9(3):106-24, Jul./set. 1978.

SA, A.L de. Oarso do anditoria. 5.ed. Săo Paulo, Atlas, 1969. V.1. 


\section{ANEXXO I}

INSTRUMMENTO DE ANALISE DA ASSISTENCIA DE ENFERMAGEM

Paciente:

R.G.: Sexo: Idade:

Data da Admissão: Quarto: Leito: Data de Saida:

No de dias analisados: Anólilse n̊: Enfermeira:

COREAN n' Clinica:

\begin{tabular}{|c|c|c|c|c|}
\hline I - LEVANTAMENTO DE DADOS NA ADMISSÃO & SIM & INCOMP. & NÃO & OBSERVAÇŌES \\
\hline 1-Dados de identificaşão completos & & & & \\
\hline $\begin{array}{l}2 \text { - Entrevista preenchida correta } \\
\text { por coupleto }\end{array}$ & & & & \\
\hline $\begin{array}{l}3 \text { - Exame físico preenchido correto } \\
\text { e por completo }\end{array}$ & & & & \\
\hline $\begin{array}{l}\text { 4- Levantamento de dados permite } \\
\text { identificar as condiçöes emocio- } \\
\text { nais do paciente no momento da } \\
\text { interneçäo }\end{array}$ & & & & \\
\hline $\begin{array}{l}5 \text { - Entrevicta e exame fícico data- } \\
\text { dos e asciondos }\end{array}$ & & & & \\
\hline
\end{tabular}




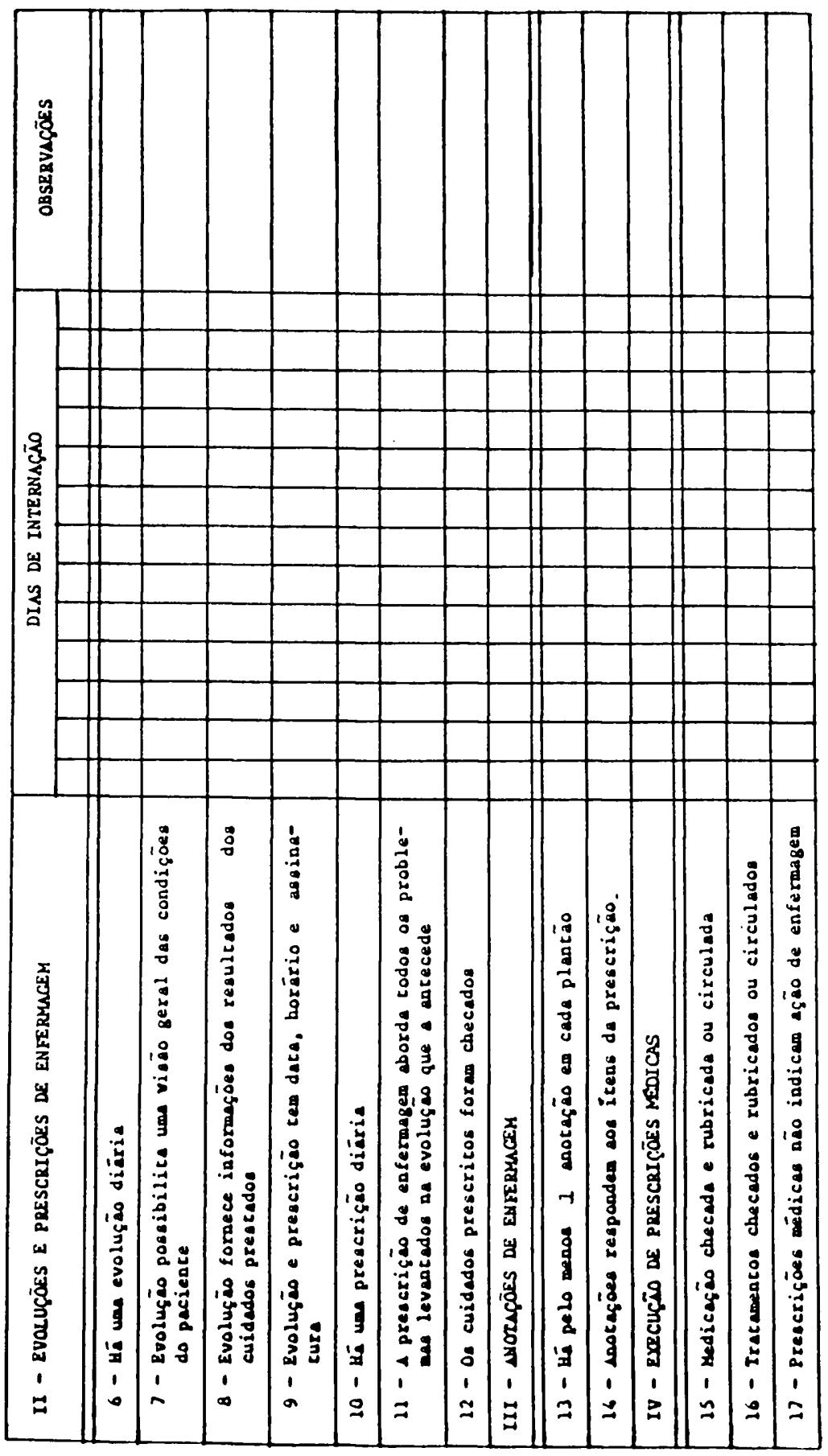




\begin{tabular}{|c|c|c|c|c|}
\hline$V$ - CCNUIÇÕES DE ALTA & SIM & INCAMP. & NAO & OBSERVACÕES \\
\hline $\begin{array}{l}18 \text { - Evolução e/ou prescri- } \\
\text { cão de enfermagem } \\
\text { dc dia da alta evi } \\
\text { denclam as orlentá } \\
\text { cóes prestadas ao } \\
\text { poclente. }\end{array}$ & & & & \\
\hline $\begin{array}{l}19 \text { - A evolução elou } \\
\text { anotaça de sajda } \\
\text { indicam ccndiçoes } \\
\text { físicas e emocio- } \\
\text { néls do paciente } \\
\text { ne ocasião da alta. }\end{array}$ & & & & \\
\hline $\begin{array}{c}\text { VI - RETORNO - CONSULTA } \\
\text { DE ENFERMAGEM }\end{array}$ & & & & \\
\hline $\begin{array}{l}20 \text { - Existe um regis- } \\
\text { tro: do retomo } \\
\text { agendado ou do } \\
\text { nao retorno na ano } \\
\text { tação ou evolução } \\
\text { de saida. }\end{array}$ & & & & \\
\hline $\begin{array}{l}21 \text { - Havendo retorno } \\
\text { agendado o pacien } \\
\text { te comfareceu. }\end{array}$ & & & & \\
\hline $\begin{array}{c}22 \text { - Dados de identifi- } \\
\text { cEção completos. }\end{array}$ & & & & \\
\hline $\begin{array}{l}23 \text { - Abordagem preenchi } \\
\text { da ccrreta e por } \\
\text { completa. }\end{array}$ & & & & \\
\hline $\begin{array}{l}24 \text { - Exame físico preen } \\
\text { chido ccrreto } \\
\text { pcr completo. }\end{array}$ & & & & \\
\hline $\begin{array}{l}25 \text { - Interccrrência pre } \\
\text { enchida correta } \\
\text { pcr completa. }\end{array}$ & & & & \\
\hline $\begin{array}{l}26 \text { - Os problemas levan } \\
\text { tados na aborda- } \\
\text { gem, Exame Fisico } \\
\text { e Intercorréncias } \\
\text { foram abordados } \\
\text { nas condutas. }\end{array}$ & & & & \\
\hline $\begin{array}{c}27 \text { - Consulta de Enfer- } \\
\text { magem assinada. }\end{array}$ & & & & \\
\hline
\end{tabular}




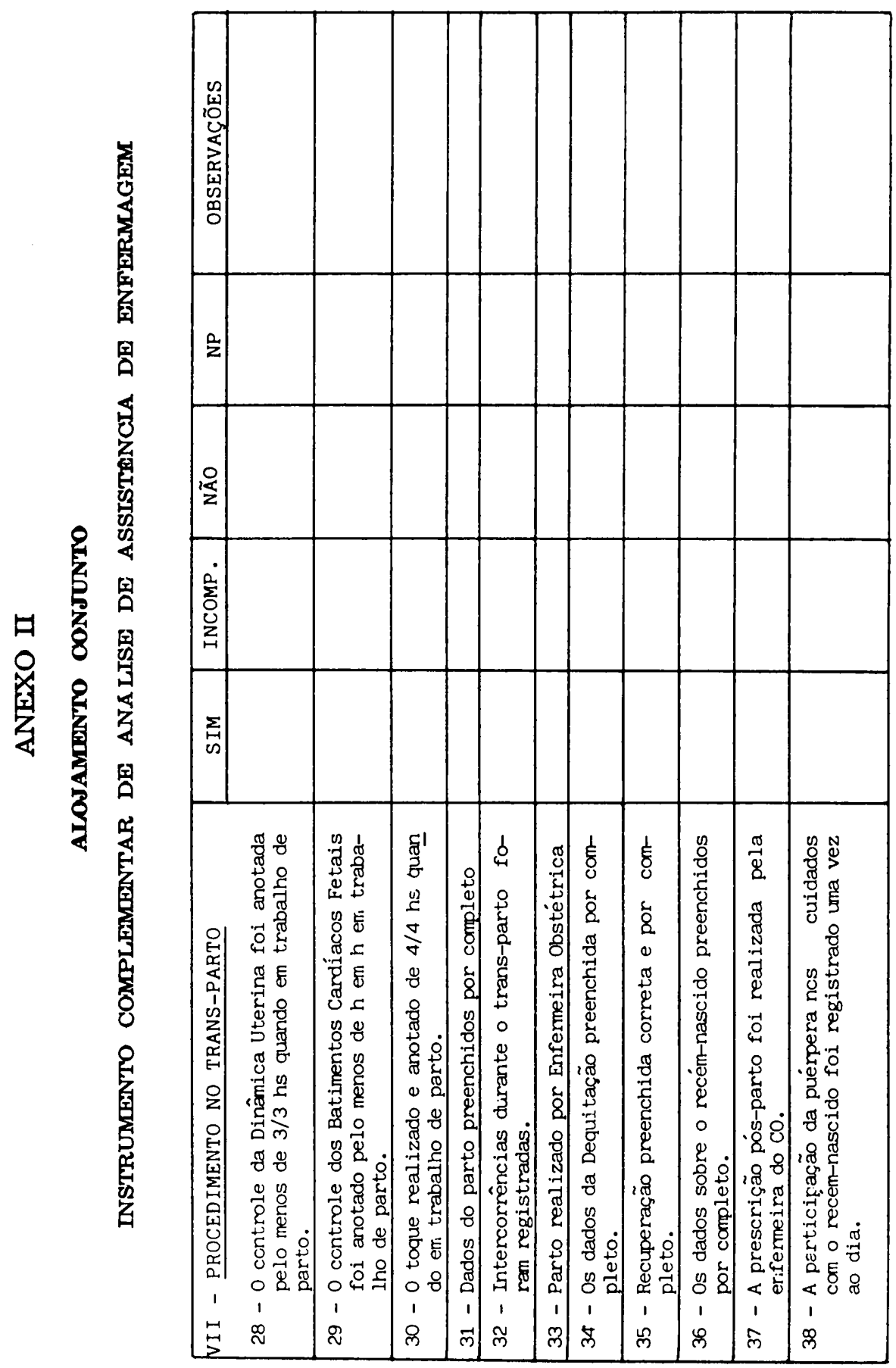




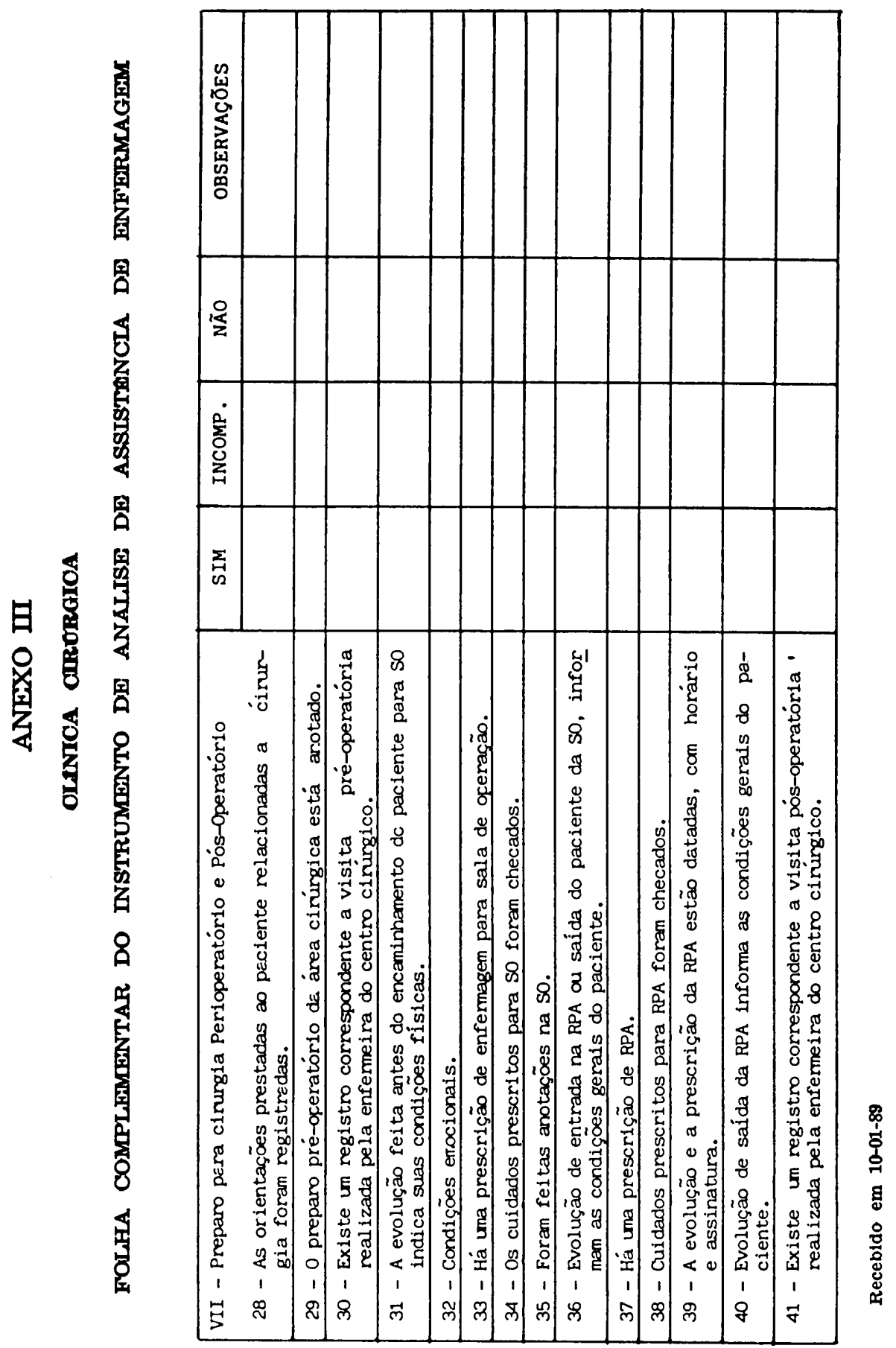

